\title{
Afectación oral de las enfermedades comunes en la infancia con carácter exantemático
}

\author{
Bascones Martínez A*, Valero Marugán A**, Carrillo de Albornoz Sainz A***, \\ Encinas Bascones A****, Bascones Martínez A*****
}

\section{RESUMEN}

Determinadas enfermedades exantemáticas de la infancia pueden cursar con manifestaciones en la región oral, siendo en ocasiones pioneras al resto de las lesiones. Para evitar complicaciones que puedan retrasar la correcta evolución y recuperación de los pacientes, y dada la morbilidad con la que cursan algunas entidades a nivel oral, se presenta una revisión en la cual se insiste en la necesidad de hacer un adecuada exploración oral ante cualquier enfermedad infecciosa o exantemática, aún cuando no consulten por síntomas a dicho nivel, para poder diagnosticar y tratar de forma precoz las lesiones orales asociadas a estas entidades.

Palabras clave: Boca, Infección, Exantema, Infancia.

\section{SUMMARY}

Some exanthematic diseases in the childhood affect in more or less importance to the oral region and highly important to know the degree of affectation to set out the guidelines for a suitable treatment at a proper level, and to avoid further complications which may delay the good evolution and soon recovery that those patients use to show. It is stressed the importance of an acute exploration of the mouth in case of any infectious or exanthematic illness, even though the consultation is not made for oral symptoms.

Key words: Mouth. Infection. Exanthema. Childhood.

Aceptado para publicación: Octubre 2005.

* $\quad$ Médico especialista en Pediatría. IMSALUD. Madrid.

** Médico especialista en Pediatría. IMSALUD. Madrid.

*** Licenciada en Odontología. Alumna de Doctorado. UCM

**** Alumno de Medicina UCM.

***** Catedrático de Medicina Bucal y Periodoncia. UCM.

Bascones Martínez A, Valero Marugán A, Carrillo de Albornoz Sainz A, Encinas-Bascones A, Bascones Martínez A. Afectación oral de las enfermedades comunes en la infancia con carácter exantemático. Av. Odontoestomatol 2006; 22 (3): 163-170.

\section{INTRODUCCIÓN}

Las enfermedades de carácter exantemático conforman un espectro de desórdenes mucocutáneos ca- racterísticos de la edad infantil (1). Los agentes virales representan el factor etiológico principal de este tipo de entidades clínicas, caracterizadas por la aparición de erupciones máculo-papulosas rojizas de dis- 
tribución muco-dérmica variable, las cuales coexisten en ocasiones con otro tipo de lesiones elementales como vesículas, pústulas o petequias. En la mayoría de los casos, se trata de procesos benignos y autolimitados, aunque en ocasiones pueden evolucionar a cuadros generalizados con compromiso de órganos internos.

Determinadas enfermedades exantemáticas de la infancia cursan con manifestaciones en la cavidad oral de severidad variable, que pueden cursar con cuadros de intenso dolor e impotencia funcional. Dada la morbilidad de las manifestaciones orales, es de gran importancia el reconocimiento de las lesiones y conocer el grado de afectación para pautar el tratamiento oportuno y evitar complicaciones que puedan retrasar la correcta evolución y pronta recuperación que suelen presentar estos pacientes (2-5).

A continuación se describen las principales enfermedades desarrolladas durante la infancia que presentan manifestaciones en la cavidad oral, enfocado hacia el diagnóstico y tratamiento de las mismas.

\section{Sarampión}

Se trata de una enfermedad infecciosa aguda de origen vírico que asienta de forma preferente durante la infancia y en adultos jóvenes $(6,7)$. La vacuna triple vírica (sarampión, rubéola y parotiditis), sintetizada a partir de virus atenuados y pautada a los 15 meses de vida con recuerdo a los 4 años de edad, reduce drásticamente las cifras de prevalencia en la población.

La enfermedad está producida por un virus RNA perteneciente al grupo de los paramyxovirus. Es extraordinariamente contagioso y se transmite de persona a persona por vía respiratoria. Tras un período de incubación de 10 días comienza el período prodrómico caracterizado por fiebre, malestar general, conjuntivitis, rinorrea y fotofobia. El cuadro clínico se instaura una vez transcurrido el período prodrómico, estimado en 5-7 días. Se caracteriza por la presencia de lesiones exantemáticas en la región retroauricular, cara y cuello, que posteriormente se extienden hacia el tronco y las extremidades. El exantema máculo-papuloso confluyente respeta las palmas y plantas de las manos y pies. La fiebre puede ser elevada y acompañada de reflejo tusígeno (8).

La lesión característica reflejo del sarampión en la cavidad oral son las manchas de köplik, desarrolladas en las etapas tempranas del curso de la infección. Se trata de lesiones puntiformes de color blanquecino rodeadas de un halo eritematoso, las cuales confluyen en ocasiones de forma localizada en la mucosa yugal. Su presencia es un signo patognomónico del sarampión, aunque no siempre aparecen. Otras manifestaciones orales descritas son la sobreinfección por Candida albicans en inmunodeprimidos, la gingivitis ulcerativa y la inflamación pericoronal. El papel de los virus en la patología gingivoperiodontal ha sido descrito recientemente, aunque se desconoce el papel del paramyxovirus en este tipo de lesiones (9-10). De forma similar al herpesvirus, el mecanismo etiopatogénico vinculado podría ser debido a la reducción de los mecanismos defensivos periodontales por efectos citotóxicos o inmunopatológicos locales favoreciendo el sobrecrecimiento de la flora subgingival (11).

El diagnóstico es eminentemente clínico, aunque en ocasiones puede requerirse la confirmación del diagnóstico debido a su baja prevalencia, la posibilidad de presentarse de forma subclínica y dado que otras afecciones víricas pueden originar cuadros clínicos similares. El análisis serológico de anticuerpos, específicamente IgM, representa el diagnóstico de laboratorio estándar, aunque también se ha descrito el análisis por PCR de frotis oral (12).

El tratamiento es sintomático, siendo altamente eficaz la prevención con la vacuna. A nivel oral, puede emplearse tratamiento coadyuvante para las lesiones gingivo-periodontales con enjuagues de clorhexidina al $0,12 \%$ junto con dieta blanda.

\section{Varicela}

Enfermedad infectocontagiosa aguda de origen vírico causada por el virus varicela-zoster (VVZ), perteneciente a la familia herpesvirus, cuyo único huésped posible es el hombre. Tras la infección primaria, que afecta principalmente a niños de entre 5-9 años y adolescentes, el virus permanece latente en nervios 
sensoriales, y ocasionalmente sobre nervios motores, con posibilidad de reactivación en forma de herpes zoster en situaciones de inmunosupresión (13).

Generalmente se trata de un proceso benigno y autolimitado en el cual las complicaciones del cuadro son infrecuentes, salvo en pacientes inmunocomprometidos en los que la neumonía, encefalitis o sobreinfecciones bacterianas cutáneas por estreptococos del grupo A pueden ser motivo de importante morbilidad del paciente (14-15).

Tras un período de incubación de 14-16 días se inicia el estadio prodrómico, caracterizado por fiebre moderada, mialgias y malestar general. El exantema característico de la enfermedad comienza en tronco y cuero cabelludo con lesiones que comienzan en forma de máculas eritematosas. Transcurridas 24 horas las lesiones pasan a la fase de pápula, vesícula y pústula, siendo signo característico que coexistan diferentes estadios de las lesiones (16). La varicela en los adultos es más grave y presenta complicaciones con mayor frecuencia, entre las que destacan la neumonía y la encefalitis.

Las lesiones orales aparecen generalmente en número pequeño (1-7). La presencia de manifestaciones orales está en relación con la agresividad del cuadro, estando siempre presentes en las formas severas (17). Cada lesión comienza como una vesícula de pequeño tamaño (3-4 mm) o ampolla, que rápidamente rompe dejando una úlcera poco profunda de fondo blanco-amarillento rodeada de un halo eritematoso. Generalmente las úlceras son poco dolorosas o asintomáticas, y plantean diagnóstico diferencial con estomatitis aftosa recurrente menor (18), salvo en casos de lesiones múltiples, cuyo cuadro asemeja a la primoinfección herpética. Las lesiones próximas pueden confluir en formas de mayor tamaño por colapso entre las mismas. Es característico que úlceras antiguas se entremezclen con lesiones nuevas en formas moderado-severas de varicela.

Actualmente la prevención se realiza con vacunas de alta eficacia y seguridad con virus vivos atenuados. Se puede administrar a partir de los 15 meses de vida en monodosis, siendo necesarias dos dosis separadas en dos meses para la inmunización de los adultos.
El tratamiento de las lesiones orales es sintomático y de carácter paliativo. Si es necesario se pueden pautar analgésicos, aunque generalmente no se requiere tratamiento alguno ya que se trata de un proceso autolimitado que cursa con escasa sintomatología dolorosa (19).

\section{Herpes simple}

Se trata de un virus neuro-dermotropo perteneciente a la familia del herpesvirus humano. Presenta dos serotipos diferentes, VHS I, responsable principalmente de las lesiones orales, y VHS 2, relacionado con las infecciones genitales, aunque ambos son capaces de inducir lesiones bucogenitales (20). La vía de transmisión es el contacto directo con las secreciones bucales y genitales para VHS 1 y VHS 2 respectivamente.

Las manifestaciones clínicas varían según la localización anatómica y en función de si se trata de infección primaria o recurrencias de la enfermedad.

La primoinfección herpética puede cursar de forma subclínica, en forma de faringitis difícilmente diferenciable de otras infecciones virales del tracto respiratorio superior o bien presentarse de forma aguda en forma de gingivoestomatitis herpética primaria (Fig 1). La primoinfección por VHS1 alcanza un pico máximo de incidencia entre los 2-4 años de edad,

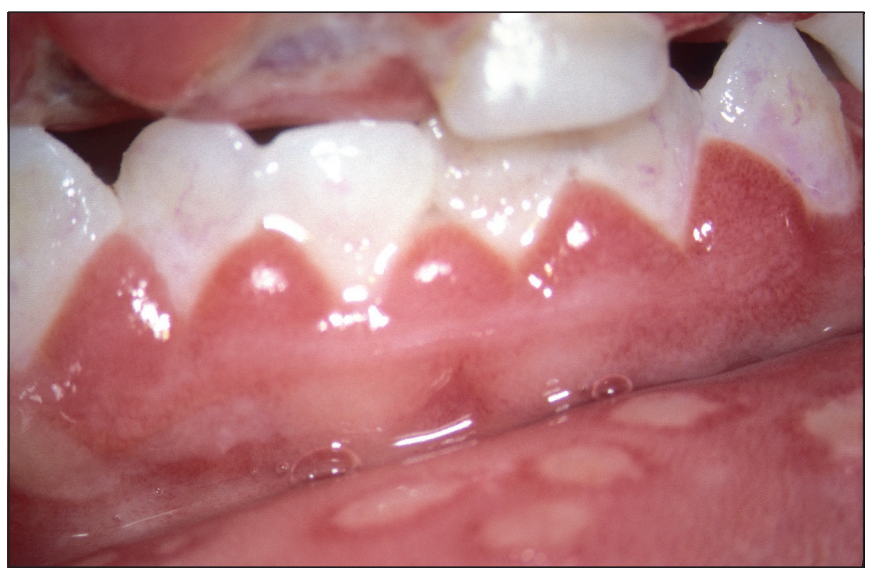

Fig. 1. Gingivitis. Inflamación gingival y presencia de vesículas en la mucosa labial. 
aunque también puede ocurrir en adolescentes y adultos (21). Clínicamente, tras un período de incubación de una semana, cursa con malestar general, fiebre, astenia, odinofagia, disfagia, adenomegalias cervicales y gingivoestomatitis. A los tres o cuatro días, coincidiendo con el descenso de la fiebre, aparece la erupción vesiculosa en la mucosa orofaríngea en forma de pequeñas vesículas agrupadas en racimos con tendencia a confluir (Fig. 2-4). Las lesiones se acompañan de dolor, sialorrea y halitosis. En ocasiones las lesiones están recubiertas por una pseudomembrana amarillenta y en la región gingival puede cursar con gingivitis aguda. Las lesiones cutáneas se manifiestan en forma de vesículas sobre una base eritematosa.

Una vez el VHS coloniza el individuo, permanece latente en los ganglios sensoriales hasta su posterior reactivación. Un 40\% de las personas infectadas presentan infecciones recurrentes desencadenadas por la exposición a estímulos tales como la exposición solar, la fiebre, la menstruación, el estrés y las situaciones de inmunosupresión. La recurrencia de la infección por VHS 1 se caracteriza por la aparición de lesiones eritemo-vesiculosas localizadas en comisuras y labios que posteriormente se transforman en pustulosas. Se trata de un proceso autolimitado, que resuelve en un período de 7-10 días sin secuelas remanentes. El aciclovir tópico reduce el período de propagación viral, aunque tiene pocos efectos sobre la sintomatología. En casos extensos o de gravedad se puede administrar aciclovir por vía oral $(22,23)$.

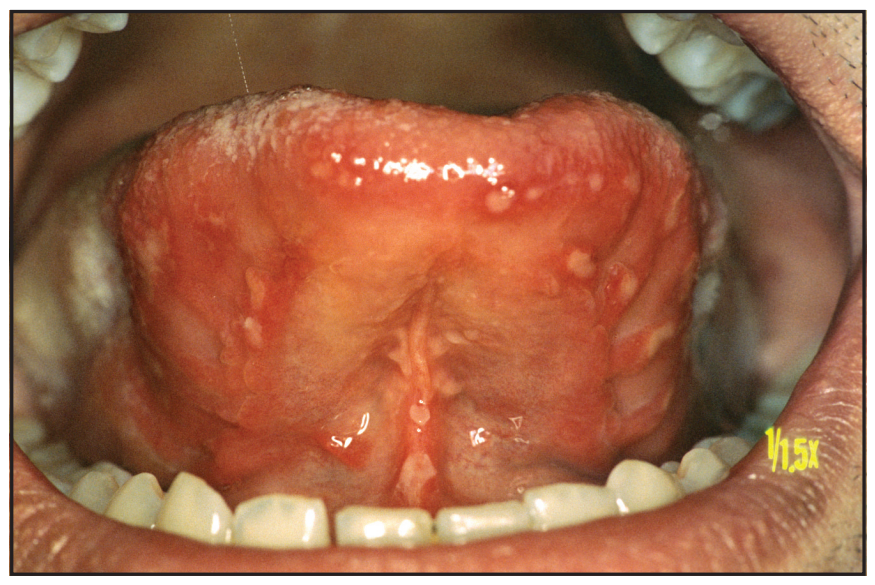

Fig. 2. Gingivoestomatitis herpética en cara ventral de la lengua.

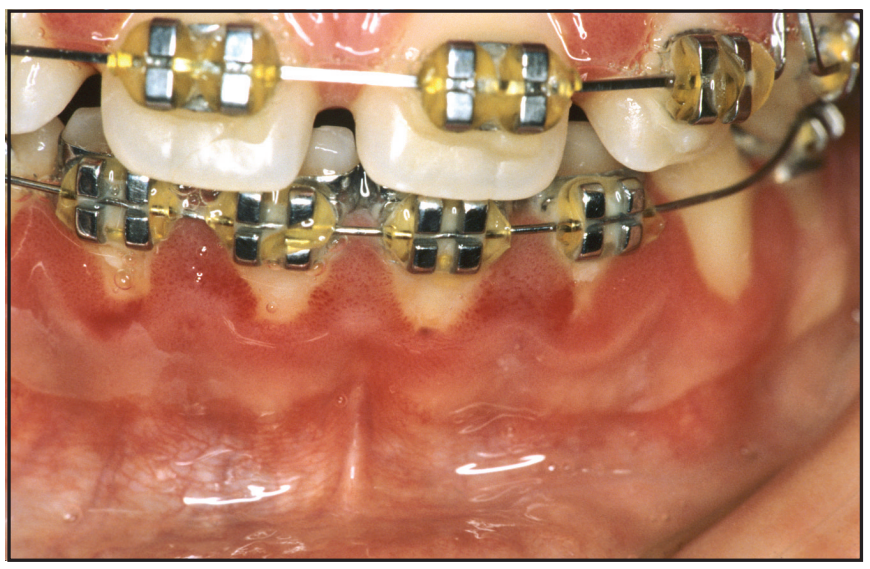

Fig. 3. Gingivoestomatitis herpética en paciente con tratamiento ortodoncico.

\section{Enfermedad mano-pie-boca}

Se trata de un proceso infeccioso muy prevalente en la edad pediátrica de carácter epidémico y de predominio estacional. El agente responsable es el virus Coxsackie A tipo 16, transmitido por vía directa a través de secreciones buco-faríngeas o bien por contacto directo con el contenido de las vesículas. Afecta a niños de 1 a 5 años durante el verano, pudiendo causar epidemias. Tras un período de incubación de 2-6 días, se inicia el cuadro clínico caracterizado por la aparición súbita de lesiones cutáneas en manos, pies y a nivel oral sin afectar el estado general. En la mucosa bucal se manifiesta en forma de lesiones de tipo aftoso, muy dolorosas, en número de 5 a 10

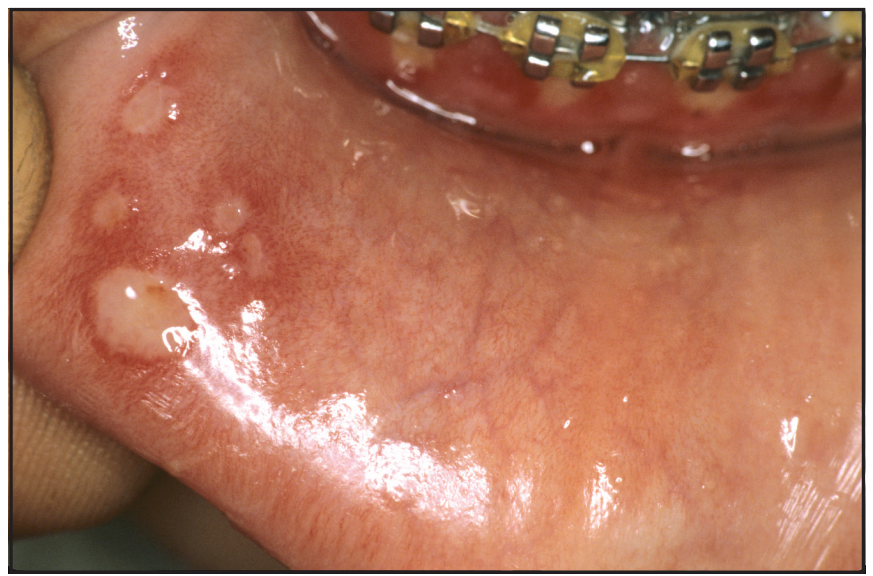

Fig. 4. Gingivoestomatitis herpética en labio inferior. 
recubiertas por una pseudomembrana amarillenta y rodeadas por un halo eritematoso. Simultáneamente existe una erupción vesiculosa cutánea en manos y pies, la cual se distribuye en número de 20 a 30 lesiones en las palmas, plantas y dedos (24).

El pronóstico es bueno, evolucionando hacia la curación espontánea en el plazo de una semana con tratamiento sintomático.

\section{Herpangina}

Se trata de una infección de afectación principalmente pediátrica producida por varios serotipos del virus Coxsackie A. Presenta un período de incubación de 2-10 días, tras el cual se desarrolla el cuadro clínico caracterizado por la aparición de un enantema periuvular, acompañado a nivel sistémico por fiebre alta, disfagia, cefalea, vómitos y dolor en extremidades. A nivel bucal, la evolución del enantema es hacia vesículas blancoamarillentas localizadas en pilares anteriores amigdalinos, paladar blando y úvula, generalmente respetando la mucosa bucal y faríngea restante, lo cual facilita el diagnóstico diferencial con la gingivoestomatitis herpética y la estomatitis aftosa (tabla 1) (25). El pronóstico es bueno y el tratamiento sintomático, pudiendo emplearse como tratamiento coadyuvante los enjuagues con anestésicos locales.

\section{Enfermedad de Pospischill Feyter}

Se observa en lactantes y niños de corta edad con debilidad general por sobreinfección con una variante del virus del herpes simple. Cursa con erupciones características en el área peribucal, bucofaríngea, puntas de los dedos y genitales externos. Tras la ulceración de las lesiones se forman costras de carácter necrótico. Generalmente se presenta acompañado de adenopatías dolorosas (19).

\section{Mononucleosis infecciosa}

Se trata una enfermedad infecciosa aguda común a la infancia, adolescencia y juventud. El agente etiológico responsable es el virus de Epstein-Barr (EBV), el cual penetra en el organismo y se localiza en los ganglios linfáticos y amígdalas. Más del $90 \%$ de la población adulta se contagia por EBV a través de las secreciones salivares, aunque sólo una pequeña fracción desarrolla el cuadro clínico tras la infección, generalmente cuando la infección prima-

TABLA 1

\begin{tabular}{|c|c|c|c|}
\hline Enfermedad & Agente & Manifestaciones orales & Manifestaciones sistémicas \\
\hline $\begin{array}{l}\text { Gingivoestomatitis } \\
\text { herpética primaria. }\end{array}$ & $\begin{array}{l}\text { Herpesvirus (DNA): } \\
\text { Herpesvirus } \\
\text { hominis } 1 \text { y } 2\end{array}$ & $\begin{array}{l}\text { Vesículas en toda } \\
\text { la mucosa oral. } \\
\text { Disfagia. }\end{array}$ & $\begin{array}{l}\text { Fiebre. } \\
\text { Malestar general. } \\
\text { Dolores articulares. } \\
\text { Adenopatías. }\end{array}$ \\
\hline $\begin{array}{l}\text { Enfermedad } \\
\text { mano-pie-boca }\end{array}$ & $\begin{array}{l}\text { Picornavirus (RNA): } \\
\text { Enterovirus: } \\
\text { Coxsackie, Echo. }\end{array}$ & $\begin{array}{l}\text { Vesículas en toda } \\
\text { la mucosa oral. } \\
\text { Disfagia. }\end{array}$ & $\begin{array}{l}\text { Vesículas en } \\
\text { manos y pies. }\end{array}$ \\
\hline Herpangina & $\begin{array}{l}\text { Picornavirus (RNA): } \\
\text { Coxsackie. }\end{array}$ & $\begin{array}{l}\text { Vesículas en úvula, } \\
\text { paladar blando } \\
\text { y amígdalas. } \\
\text { Disfagia. }\end{array}$ & $\begin{array}{l}\text { Fiebre. } \\
\text { Vómitos. } \\
\text { Dolor abdominal. }\end{array}$ \\
\hline
\end{tabular}

\footnotetext{
*López-Sánchez y cols, 2003.
} 
ria se retrasa hasta la adolescencia o edad adulta $(26,27)$.

Presenta un periodo de incubación de 30 a 50 días seguido de un cuadro prodrómico de 4 a 5 días de malestar general y cefaleas, tras el cual comienza el cuadro clínico característico de fiebre elevada, faringoamigdalitis con odinofagia y adenopatías cervicales. Aproximadamente el $50 \%$ de los pacientes presentan esplenomegalia y solamente un $10 \%$ hepatomegalia, aunque las alteraciones de la función hepática existen en la práctica totalidad de los casos. En ocasiones puede aparecer un exantema máculo-papuloso en tronco y regiones proximales de las extremidades, acompañado de úlceras orales en cavidad bucal y faringe. En la analítica destaca la leucocitosis con franca linfomonocitosis, junto con la presencia de anticuerpos heterófilos detectados mediante el test de Paul-Bunnell, positiva en la mayoría de los casos. El tratamiento es sintomático siendo útil el reposo con antitérmicos y analgésicos (28).

\section{Escarlatina}

Enfermedad infectocontagiosa exantemática de origen bacteriano y de distribución universal que afecta a individuos a partir de los tres años de edad. El agente responsable es el estreptococo Betahemolítico del grupo $\mathrm{A}$, a través de una exotoxina eritrogénica. La enfermedad comienza en forma de faringoamigdalitis convencional, apareciendo a los dos días el exantema característico consistente en máculas del tamaño de una cabeza de alfiler de color rojo vivo. Las lesiones inician su aparición en tronco y cuello, extendiéndose posteriormente hacia extremidades y cara, aunque preservando la región perioral, palmas y plantas. El exantema es muy intenso en pliegues (axilas e ingles) pudiendo aparecer petequias lineales (líneas de Pastia).

A nivel bucal cursa con un exantema muy marcado en la lengua, la cual aparece cubierta por un exudado blancoamarillento. Las papilas linguales sobresalen hiperémicas, estando engrosadas y dando el aspecto de lengua aframbuesada.

Transcurridos 6 o 9 días desaparece la fiebre, la amigdalitis y el exantema. En esta fase es caracterís- tica la descamación de la piel incluso a nivel palmar y plantar, aunque no se desarrolla en todos los casos. Las complicaciones son raras, aunque pueden aparecer las comunes a cualquier infección estreptocócica, tales como meningoencefalitis o glomerulonefritis (29).

El diagnóstico es eminentemente clínico confirmándose siempre con el aislamiento del estreptococo Beta-hemolítico en el frotis faríngeo en cultivo de agar-sangre.

El tratamiento consiste en la administración de penicilina tres veces al día durante 8-10 días.

\section{Síndrome de Kawasaki o síndrome mucocutáneo ganglionar}

Se trata de una vasculitis febril, exantemática, multisistémica y de carácter epidémico. A pesar de su baja incidencia, más elevada en países asiáticos, presenta una gran trascendencia clínica, ya que se presenta entre los 9 meses y los 6 años de edad, y aproximadamente el $20 \%$ de los niños no tratados desarrolla anomalías coronarias, siendo el aneurisma la complicación más destacada (30).

La etiología es desconocida, aunque las características epidemiológicas y clínicas sugieren que se trata de una entidad infecciosa. Un nuevo coronavirus humano denominado New Haven (HCOV-NH) se ha descrito recientemente como un posible agente causal (31).

Tras un pródromo de fiebre y malestar, aparecen los signos y síntomas característicos de la enfermedad (Tabla 2).

Debido a que no se dispone de prueba diagnóstica específica, para el diagnóstico del síndrome de Kawasaki, se requiere la presencia de fiebre durante al menos 5 días y un mínimo de 4 de las 5 características clínicas. La ecocardiografía tridimensional puede mostrar aneurismas coronarios aproximadamente en el $20-25 \%$ de los pacientes no tratados durante los 10 primeros días desde el inicio de la fiebre. Generalmente se producen de 1-4 semanas después del comienzo de la enfermedad. El porcen- 


\section{TABLA 2.- CARACTERÍSTICAS CLÍNICAS DEL SÍNDROME DE KAWASAKI}

- Inyección conjuntival bilateral sin exudado.

- Boca y faringe eritematosas, lengua aframbuesada, labios rojos y fisurados.

- Erupción cutánea polimorfa generalizada eritematosa que puede ser morbiliforme, maculopapular o escarlatiniforme.

- Cambios en las extremidades consistentes en induración de manos y pies con palmas y plantas eritematosas y descamación periungular.

- Linfadenopatía cervical aguda no supurativa con al menos un ganglio de $1,5 \mathrm{~cm}$ de diámetro.

taje actual de casos mortales es menor del 0,01\%, siendo el infarto de miocardio por oclusión coronaria la principal causa de muerte.

El tratamiento durante la fase aguda tiene como objetivo reducir la inflamación del miocardio y de la pared de la arteria coronaria. El tratamiento con dosis altas de Iglv (inmunoglobulina intravenosa) y ácido acetilsalicílico iniciado durante los primeros 10 días desde la aparición de la fiebre disminuye sustancialmente la progresión hacia dilatación arterial coronaria y aneurismas, consiguiendo una resolución significativamente más rápida de la fiebre y otros indicadores de inflamación aguda. Se recomienda una dosis de $2 \mathrm{~g} / \mathrm{kg}$ de Iglv como dosis única administrada durante 10-12 horas. A pesar de este tratamiento inmediato, entre el 2 y el $4 \%$ de los pacientes, desarrollará anomalías de las arterias coronarias.

\section{BIBLIOGRAFÍA}

1. A. Zambrano, V. López-Barrantes. A. Torrelo. Atlas de Dermatología Pediátrica. Ed. Médicas Jims, 2004.
2. Trevisan A, Morandin M, Frasson C, Paruzzolo P, Davanzo E, Di Marco L, Fabrello A, BorellaVenturini M. Prevalence of childhood exanthematic disease antibodies in paramedical students: Need of vaccination. Vaccines, 2005:1-6.

3. J. M. Mascaró. Claves para el diagnóstico Clínico en las Dermatosis. Harcourt Brace, 1997.

4. Kayshon, Mei Kane, MD et col. Colour Atlas and Synopsis Pediatric Dermatology.Mc Graw-Hill Interamericana 2002.

5. William M. Pediatric Prissey Care. Ed. Mosby, 1994.

6. Katz J, Guelmann M, Stavropolous F, Heft $M$. Gingival and other oral manifestations in measles virus infection. J Clin Periodontol. 2003;30(7): 665-8.

7. de Ory F, Sanz JC, Echevarria JE, Mosquera Mdel M, Guisasola ME. Comparison of serological procedures used for the diagnosis of viral exanthema in laboratories participating in the measles elimination plan. Enferm Infecc Microbiol Clin. 2004 Jun-Jul;22(6):319-22.

8. American Academy of Pediatrics. Pickering L K ed. Red Book 2003. Report of the Committee on Infections Diseases. 26th edition Elk Grove Village, II American Academy of Pediatrics; 2003.

9. Contreras A, Umeda M, Chen C. Relationship between herpesvirus and adult periodontitis and periodontopathic bacteria. J Periodontol;70: 478-84.

10. Bascones-Martínez A. Escribano-Bermejo M. Enfermedad periodontal necrosante: una manifestación de trastornoz sistémicos. Med Clin (Barc) 2005;125(18):706-13.

11. Contreras A, Zadeh H, Nowzari H, Slots J. Herpesvirus infection of inflamatory cells in human periodontitis. Oral Microbiology and immunology; 14: 206-12.

12. van Binnendijk $R$, van den Hof $S$, van den Kerkhof H, Kohl R, Woonink F, Berbers G. 
Evaluation of Serological and Virological Tests in the Diagnosis of Clinical and Subclinical Measles Virus Infections during an Outbreak of Measles in The Netherlands. Journal of infectious diseases. 2003:898-903.

13. Kolokotronis A, Louloudiadis K, Fotiu G, Matiais A. Oral manifestations of infections due to varicella zoster virus in otherwise healthy children. J Clin Pediatr Dent 2001;25(2):107-12.

14. Kakourou T, Theodoridou M, Mostrou G, Syriopolou V, Papadogeorgaki H, Constantopoulus A. Herpes zoster in children. J Am Acad Dermatol 1998;31:207-12.

15. Peterson CL, Vugia DJ, Meyers HB, Chao SM, Vogt J, Lanson J, Brunell PA, Kim KS, Mascola BL. Risk factors for invasive group A streptococcal infections in children with varicella: a case-control study. Pediatr Infect Dis J 1996;15:151-6.

16. Poulsen A, Cabral F, Nielsen J, Roth A, Lisse I, Aaby P. Growth, morbidity and mortality after chickenpox infection in young children in GuineaBissau. Journal of Infection. 2005;13:307-12.

17. Febton Sj, Unkel JH. Viral infections of the oral mucosa in childres: A clinical review. Pract Period Aesth Dent. 1997; 9: 683-92.

18. Bascones A, Figuero E, Esparza G. Úlceras orales. Med Clin (Barc). 2005; 125(15): 590-7.

19. Bascones Martínez A. Medicina bucal. $3^{\mathrm{a}}$ ed. Barcelona: Ariel y Ediciones Avances; 2004.

20. Contreras A, Slots J. Herpesviruses in human periodontal disease. J Periodont Res. 2000;35: 3-16.

21. Stoopler ET. Oral herpetic infections (HSV 1-8). Dent Clin N Am. 2005:15-29.

22. Woo SB, Lee SF, Mass B. Oral recurrent herpes simplex infection. Oral Surg Oral Med Oral Pathol Oral Radiol Endod. 1997;83:239-43.

23. Ralph J. Wadgwood, S. P. Davis, C. G. Ray y V. C. Kalley. Infections in Children. Ed. Doyme, 1994.
24. Bruce AJ, Rogers RS. Acute oral ulcers. Dermatol Clin. 2003;21:1-15.

25. Sánchez A, Guijarro B, Hernández-Vallejo G. Repercusiones humanas de la fiebre aftosa y otras enfermedades víricas afines. Med Oral 2003;8: 26-32.

26. Niederman JC, Evans AS, Subrahmanyan L, McCollum RW. Prevalence, incidence and persistence of EB virus antibody in young adults. N Engl J Med 1970; 282:361-5.

27. Rickinson AB, Kieff E. Epstein-Barr virus. In: Field's virology. 3rd ed. Vol. 2. Philadelphia: Lippencott-Raven, 1996:2397-446.

28. Sitki-Green D, Hood R. Biology of Epstein-Barr Virus during Infectious Mononucleosis. The Journal of Infectious Diseases 2004;189:48392.

29. Sanz JG, Bascones A, Martín F, Sáez-NietoA. Escarlatina recurrente por reinfección reciente causada por cepas no relacionadas de Streptococcus pyogenes. Enferm Infecc Microbiol Clin 2005;23:388-9.

30. Kato H, Akagi T, Sugimura T, Sato N, Kazue T, Hashino K, et al. Kawasaki disease. Coron Artery Dis 1995;6:194-206.

31. Esper F, Shapiro ED, Weibel C, Ferguson D, Landry ML, Kahn JS. Association between a novel human coronavirus and Kawasaki disease. J Infect Dis. 2005 Feb 15;191(4):499502.

\section{CORRESPONDENCIA}

Prof. Antonio Bascones

Departamento de Medicina y Cirugía Bucofacial.

Facultad de Odontología.

Universidad Complutense de Madrid.

Plaza Ramón y Cajal, s/n

28040. Madrid, España

Correo electrónico: antbasco@odon.ucm.es

Fax: 915338064 